\title{
ASPECTOS GENERALES DE LA INCOMPETENCIA DE JURISDICCIÓN EN EL JUICIO LABORAL
}

\section{EDDY MARTÍNEZ RIVERA}

Profesor Asociado de Derecho de la Seguridad Social Universidad Centroamericana

$\mathrm{E}$ 1 objetivo fundamental de este artículo es analizar de forma general lo que es la incompetencia de jurisdicción en el juicio laboral de una manera breve, precisa, concisa y práctica. De igual manera en este contenido no se comprenden todos los matices y/o casos típicos en donde surge este incidente procesal por razón de espacio y que en números futuros de ésta Revista podrían ser incluidos de forma parcial. He creído útil abordar el presente tema siguiendo un orden académico en aspectos del derecho procesal para una mejor comprensión sin ahondar en doctrina jurídica por motivos de praxis jurídica y pretender con ello una identificación objetiva entre lo establecido por el sistema jurídico y casos concretos, delimitando los aspectos relevantes porque este incidente puede enfocarse en consideración a la competencia de los Jueces del Trabajo y que puede ser:

a) Por razón de la materia: En esta nos podemos encontrar con casos típicos como los originados por las acciones laborales que tienen origen en una contratación por servicios profesionales, en un acto administrativo de nombramiento de funcionarios para cargos públicos, en incidente de nulidad post sentencia que afecta la competencia del Juez del Trabajo que conoció de la demanda laboral. Los jueces del trabajo, dice el Arto. 273 C.T. "conocerán única y exclusivamente de la materia laboral; donde no los hubiere, los Jueces de Distrito Civil y Locales asumirán sus funciones." También el Código del Trabajo concede competencia especial en determinados asuntos.

b) Por razón de la cuantía: Resulta que al día de hoy algunos empleadores y/o sus asesores jurídicos consideren el monto económico reclamado de una demanda laboral como referencia para invocar incompetencia de jurisdicción porque la misma se interpuso ante la autoridad que se estima incompetente por esa causa. Esta opera por lo general en aquellos Distritos Judiciales donde no se han nombrado Jueces del Trabajo y por disposición de la ley las demandas laborales son conocidas por los Jueces de lo Civil, sean de Distrito 
o Locales. El Arto. 276 C.T. establece: "Los jueces del trabajo conocerán de toda demanda laboral, independientemente de la cuantía."

c) Por razón del territorio: Conforme lo dispone el mismo Código Laboral tendrán competencia: El Juez del lugar en donde se celebra el contrato o el Juez en donde se ejecutará el trabajo, a elección del demandante; y cuando se trate de contratos celebrados con trabajadores nicaragüenses para la prestación de servicios en el extranjero, será Juez competente el del lugar del territorio nacional en donde se celebró el contrato de trabajo (Arto. 277 C.T.).

No obstante la competencia de los Jueces del Trabajo conforme lo expuesto anteriormente, también puede ser invocada la incompetencia de jurisdicción por declinatoria o inhibitoria o por inmunidad de jurisdicción, por ejemplo.

\section{De los incidentes}

Toda cuestión accesoria al juicio principal que requiera pronunciamiento especial con audiencia de las partes, se tramitarán como incidente (Arto. $237 \mathrm{Pr}$ ). Sin embargo el Juez tiene la facultad de rechazar el incidente que no tenga conexión alguna con el asunto que es materia del juicio (Arto. 238 Pr.) Cuando el juez rechaza un incidente por improcedente la parte que se considera afectada puede impugnar esa decisión judicial ante el Superior Jerárquico competente (Arto. 249 Pr.) Las excepciones dilatorias se decidirán por los trámites de los incidentes antes de continuar con la causa y las perentorias se resolverán con la sentencia definitiva (Arto. 827 Pr).

El Incidente se define como un "litigio accesorio que se suscita con ocasión de un juicio, normalmente sobre circunstancias de orden procesal, y que se decide mediante una sentencia interlocutoria". ${ }^{1}$ En otras palabras el incidente es aquella cuestión accesoria de un juicio que en su esencia trata de embarazar la acción intentada, aunque su verdadera naturaleza es la de propiciar un procedimiento mas expedito y transparente. Estos requieren de un pronunciamiento especial con audiencia de las partes por lo que se dice que es un juicio o proceso declarativo especial siendo el procedimiento que ventila la misma cuestión incidental. Dice el Arto. 237 Pr.: “Toda cuestión accesoria de un juicio, con exclusión de los verbales, que requiera pronunciamiento especial con audiencia de las partes, se tramitarán como incidente y se sujetará a las reglas de este título, si no estuviere señalado por la ley una tramitación especial”

Toda cuestión incidental para que sea procedente tiene obligatoriamente que reunir o cumplir los siguientes requisitos importantes: ${ }^{2}$

COUTURE, Vocabulario Jurídico, 1993, págs. 325-326.

2 ORTIZ URBINA Roberto J., Derecho Procesal Civil. Editorial Bitecsa. Managua. 1995, págs. 85 y 86. 
1.1 Accesoriedad: El incidente tiene que tener una dependencia "de la pretensión principal, si no hay relación, si hay independencia o autonomía, no puede incluirse en la figura y no sería atendible."

1.2 Conexidad: Debe haber "una vinculación clara y precisa con la causa principal".

1.3 Oportunidad: "Requisito que exige que la cuestión se proponga " $\tan$ pronto llegue al conocimiento de la parte." Ese tan pronto expresa la Corte Suprema de Justicia es dentro de veinticuatro horas. Preferimos decir la siguiente audiencia a mas tardar."

Tramitar el Incidente conforme a derecho quiere decir que el Juez o Tribunal una vez interpuesta cualquiera de las excepciones que deben resolverse de previo, como las dilatorias, deberá mandar a oír a la otra parte para que conteste lo que tenga a bien dentro de tres días y al término de ese tiempo si el Juez o Tribunal considerare que a su juicio no hubiere necesidad de prueba dictará la resolución que fuere procedente (Arto. 244 Pr.) Si fuera necesario rendir pruebas, la autoridad judicial abrirá el incidente a pruebas con todos cargos (Arto. 245 Pr.). Sobre esto en lo laboral al no haber en el Código del Trabajo procedimiento especial como lo señala el Código de Procedimiento Civil (Pr.) para las demandas civiles, los Jueces abren el incidente a un período de pruebas que sea menor al período de prueba ordinario del mismo proceso o juicio laboral.

Los incidentes en el proceso laboral están regulados del Arto. 294 al 298 C.T., y de forma general se determina:

a) Toda cuestión accesoria al juicio principal que requiera pronunciamiento especial con audiencia de la parte contraria se tramitará como incidente;

b) El Juez, si lo estima a bien, puede rechazar el incidente;

c) Si el Juez declara improcedente el incidente, se podrá impugnar en segunda instancia;

d) Si el incidente tiene origen en un hecho dentro del juicio se deberá promover por la parte que tenga conocimiento al día siguiente hábil, pero si gestionara en el proceso posterior a ese conocimiento se le rechazará, salvo que sean vicios que anule el proceso o de una circunstancia especial para la consecución del juicio; y

e) Con la salvedad de trámite especial que señale el Código, todo incidente se resolverá en la sentencia, con excepción de el incidente de ilegitimidad de personería e incompetencia de jurisdicción, los que deberán resolverse previamente. 


\section{Oportunidad para promover el incidente}

Nuestro Código de Procedimiento Civil determina los siguientes momentos para promover el incidente: 1) Cuando naciere de un hecho anterior al juicio o coexistente con el principio del juicio, se deberá promover por la parte antes de cualquier gestión principal del pleito, en caso contrario se rechazará salvo que sea de los que puedan anular el proceso o que se traten de una circunstancia esencial para la ritualidad del juicio (Arto. 239); 2) Que el hecho acontezca durante el juicio y en este caso se deberá promover tan pronto como el hecho llegue a conocimiento de la parte respectiva, pero si la parte gestionare posterior a ese conocimiento se rechazará de plano, salvo que se trate de alguno de los vicios o circunstancias a que se refiere la parte segunda del artículo anterior (Arto. 240); y 3) Si todos los incidentes cuyas causas existan simultáneamente deberán promoverse a la vez, en caso contrario se aplicará lo dispuesto en el Arto. 239 anterior, segundo párrafo (Arto. 241).

\section{Concepto procesal de Excepción}

"En Derecho Procesal, título o motivo que, como medio de defensa, contradicción o repulsa, alega el demandado para excluir, dilatar o enervar la acción o la demanda del actor...” '3. En nuestro Código de Procedimiento Civil (Pr) se conceptualiza como "la exclusión de la acción o la contradicción por medio de la cual el demandado procura diferir o extinguir la acción intentada.” (Arto. 818 Pr.)

\section{Diferencia entre el Proceso Civil y el Proceso Laboral}

En lo que respecta a las excepciones dilatorias existe una marcada diferencia en cuanto al momento de oponer las excepciones entre el proceso civil y el proceso laboral, ya que en el proceso civil ordinario las excepciones dilatorias entre la que se encuentra la de Incompetencia de Jurisdicción se interponen dentro del término ordinario señalado para la contestación de la demanda y pasado ese término no se admitirá ninguna, salvo las que se refieran a nulidad absoluta insubsanable y las provenientes de causas supervinientes; debiéndose resolver éstas por los trámites de los incidentes antes de procederse adelante. El oponente no contesta la demanda sino que se limita a excepcionar la acción y el Juez deberá tramitarla antes de continuar con la demanda principal y una vez resuelta la excepción se le concederá al demandado nuevo traslado para que conteste la demanda (Artos. 824, 827 y 830 Pr.). Por su parte el Arto. 828 Pr. establece que cuando se trate de

3 CABANELlAS Guillermo, Diccionario Enciclopédico de Derecho Usual, 1997, Tomo III, página 616. 
juicios civiles verbales, posesorios y sumarios, estas excepciones se substanciarán y resolverán con la causa principal, pero las de incompetencia de jurisdicción, ilegitimidad de personería, evicción y saneamiento y litispendencia se resolverán de previo en estos juicios. Como ejemplo referencial en cuanto a las excepciones dilatorias en juicios ordinarios verbales en el B.J 1966 Pág 329, Consulta del 27 de mayo, contenido en el Nuevo Diccionario de Jurisprudencia Nicaragüense de Juan Huembes y Huembes de 1971, la Excelentísima Corte Suprema de Justicia dijo:

"El demandado debe proponer las excepciones en la contestación de la demanda y se sustanciarán y resolverán junto con la causa principal, es decir, en la sentencia definitiva; salvo las de incompetencia de jurisdicción, iligitimidad de personería, transacción, cosa juzgada, finiquito y litispendencia, que si bien deben proponerse en la contestación de la demanda, el Juez debe resolverlas de previo, en sentencia interlocutoria que deberá dictar dentro de tercero día.

\section{Excepciones en el Proceso Laboral}

Todas las excepciones se resolverán en la sentencia definitiva, pero los excepciones de ILEGITIMIDAD DE PERSONERÍA e INCOMPETENCIA DE JURISDICCIÓN, opuestas deberán resolverse de previo (Arto. 320 C.T.). O sea estas dos excepciones deben resolverse inmediatamente de interpuestos para poder proseguir con el proceso judicial laboral. Cuando la ley exige "resolver de previo" es porque estamos frente a un problema en estricto sentido jurídico y no habiendo resolución no se podría determinar la relación procesal de las partes con el objeto del litigio. Por ende las excepciones como incidentes, constituyen todo hecho que en virtud de la ley, difieren o extingue la acción interpuesta. En otras palabras no se pueden interponer excepciones no señaladas expresamente por la ley. Las excepciones deben oponerse en la contestación de la demanda o contra demanda, justificándose los hechos en que se fundan excepto cuando se fundaren en hechos sobrevenidos, los que son aquellos cuyo conocimiento a la parte procesal llegan con posterioridad a la contestación de la demanda (Arto. 320 C.T.) Cuando una parte procesal interpone un incidente propiamente en sentido jurídico, puede a la vez excepcionar la acción y la autoridad judicial deberá tramitar el incidente como tal ya que por lo general es el incidente por nulidad el que se interpone y de darle lugar a éste por consecución lógica la demanda es prácticamente nula. En otras palabras de no ser cierto el incidente las excepciones no tendrían el fundamento creado por la parte incidentista y el Juez deberá recharzarlas de plano. 
Determina el Código que únicamente las excepciones perentorias podrán oponerse en cualquier estado del juicio laboral. Cuando se oponen las excepciones fuera del término señalado por el Arto. 320 CT., y no siendo las de Ilegitimidad de personería o de incompetencia de jurisdicción, el Juez en la Sentencia no está obligado a pronunciarse sobre la admisibilidad o no de las mismas. ${ }^{4} \mathrm{Si}$ son de las que de previo debe pronunciarse el Juez, la parte interesada al ser rechazadas o declaradas que "no ha lugar a la excepción de incompetencia de jurisdicción", por ejemplo, puede interponer en contra de esta resolución cualquiera de los medios de impugnación señalados por el Código del Trabajo. En otras palabras, de lo que resuelva el Juez en este trámite, se podrán interponer los medio de impugnación regulados por el Código del Trabajo del Arto. 348 al 359. Por lo general el empleador es el que hace uso del recurso de apelación en los incidentes que en materia laboral requieren especial y previo pronunciamiento, con fines eminentemente dilatorios en muchos casos, y hasta que el Tribunal de Apelaciones competente resuelva se proseguirá con la sustanciación de la demanda en primera instancia en caso de que se confirme el "no ha lugar al incidente" declarado por el Juez en su resolución apelada.

Exige la ley laboral que las excepciones opuestas tengan fundamento. Significando que el que la opone expresamente debe señalar en su escrito esas razones de peso jurídicamente, pues de lo contrario se colige que es con el fin de retrasar el proceso y en ese caso el Juez la rechazará de inmediato no dándole al interesado el derecho de hacer uso de los medios de impugnación establecidos por el Código del Trabajo (Artos. 320 y 321). Podría manifestarse este caso cuando la parte demandada, verbigracia, al contestar la demanda se limite a decir que la contesta oponiendo las excepciones de transacción extrajudicial y pago sin fundamentarlas a como lo exige la ley laboral, o simplemente expresa que el Juez es incompetente para conocer la demanda. Otra manera podría ser que la parte demandada presente escrito en la cual diga que contesta la demanda laboral oponiendo las excepciones tales y tales, sin contestar a su vez cada uno de los puntos de la demanda laboral, sin expresar los hechos en que se fundan las excepciones opuestas.

Dentro de la administración de Justicia en materia laboral algunos Jueces por un lapsus calami al momento de la sustanciación del juicio no le han dado el verdadero trámite a las excepciones opuestas y que deban resolverse de previo. El juzgador se tiene que apegar al procedimiento normado para los juicios verbales conforme el Arto. 1963 Pr., según jurisprudencia del Tribunal de Apelaciones

\footnotetext{
${ }^{4}$ MARTINEZ ORDOÑEZ Octavio y CASTELLON TORREZ Saúl, Diccionario de Jurisprudencia Laboral de Occidente 1997-2001, 2002, pág. 83.
} 
de Occidente. Esta norma en lo pertinente establece que la Incompetencia de Jurisdicción opuesta se resolverá de previo, señalándose para el efecto el término de tres días y de haber necesidad de apertura a pruebas se observará lo pertinente por el Juzgador. El actuar del juez, en el caso planteado, conlleva a la nulidad de todo lo actuado lo que repercute directamente en los intereses de una de las partes procesales. En un caso concreto el Juez que conocía de la demanda laboral no tramitó como incidente de previo y especial pronunciamiento la excepción de incompetencia de jurisdicción opuesta por la parte demandada, sino que tuvo por contestada la demanda laboral resolviendo en relación a las excepciones opuestas que "no ha lugar, éstas se resolverán en la sentencia definitiva conforme el Arto. 320 CT.", no interpretando correctamente el judicial la parte final de dicho artículo, sino que mandó a abrirse a pruebas la causa por el término de ley. Como vemos este actuar negligente de la autoridad judicial acarrea serios perjuicios al trabajador ya que de continuarse el caso en determinado momento llegaría a conocimiento del Tribunal de Apelaciones competente el que declarará nulo todo lo actuado ordenando al Juez A-Quo tramitar el incidente conforme derecho y resolver lo que corresponda. Así tenemos la Sentencia No. 99, de las once y cuarenta y cinco minutos de la mañana del 17 de agosto de 1999, páginas 587/588, Considerando II, Sala Civil y Laboral del Tribunal de Apelaciones de la Circunscripción Occidental: ${ }^{5}$

"NULIDAD PROCEDIMENTAL.- En la presente causa la Juez a-quo no tramitó como incidente de previo y especial pronunciamiento la excepción de incompetencia de jurisdicción opuesta por el demandado, mandando a oír a la contraria y abriéndolo a pruebas por tres días como lo señala el Arto. 1963 Pr., para los juicios verbales. En lugar de ello, por auto de las cuatro y treinta y dos minutos de la tarde del dieciséis de noviembre de mil novecientos noventa y ocho, la Juez de la causa tuvo por contestada la demanda laboral, al Lic. P.R., como parte en el juicio y como representante legal de la parte demandada, y de las excepciones opuestas manifestó: "no ha lugar, estas se resolverán en la sentencia definitiva, todo de conformidad al Arto. 320 C.T."; y por auto posterior de las cuatro y veinte minutos de la tarde del veintidós de febrero de mil novecientos noventa y nueve, abrió el juicio a pruebas por el término de seis días de conformidad al Arto. 327 C.T., no habiéndose tramitado la excepción de incompetencia de jurisdicción como un incidente de previo y especial pronunciamiento; por tanto no queda a la Sala más que declarar nulo todo lo actuado a partir del auto de las cuatro y veinte minutos de la tarde del veintidós de febrero de mil novecientos noventa y nueve inclusive en adelante, debiendo la Juez tramitar el incidente conforme a derecho y resolver lo que corresponda."

${ }^{5}$ Ibídem. Pág. 132. 
Para el caso de la excepción de ilegitimidad de personería y de incompetencia de jurisdicción la ley expresamente ordena que deberán resolverse de previo por lo que el Juez no puede a su arbitrio tomar la decisión de actuar procesalmente de forma contraria y en lo que respecta al procedimiento a seguir para esas excepciones la Sala Civil y Laboral del Tribunal de Apelaciones de la Circunscripción Occidental, en su Sentencia No. 115, de las diez y quince minutos de la mañana del 23 de septiembre de 1999 y en lo conducente dijo: "La ley expresa no deja dicha tramitación al arbitrio del juez, por lo que este no puede ni debe en ese caso aplicar el Arto. 321 C.T., porque violenta o infringe el Arto. 7 Pr., eventualmente el Arto. X del título preliminar del Código Civil (Arto. 404 C.T.)...": 6

Las disposiciones legales citadas en la anterior jurisprudencia establecen: a) "Arto. 7 Pr., Los procedimientos no dependen del arbitrio de los Jueces, los cuales no pueden restringirlos ni ampliarlos, sino en los casos determinados por la ley. Las partes están autorizadas para renunciar los procedimientos establecidos a su favor en lo civil, de una manera expresa. Tácitamente sólo podrán hacerlo en los casos señalados por la ley.”; b) “Arto. X Título Preliminar del Código Civil: Los actos ejecutados contra leyes prohibitivas o preceptivas son de ningún valor, si ellas no designan expresamente otro efecto para el caso de contravención."; y c) "Arto. 404 C.T.: Las autoridades laborales aplicarán por analogía el procedimiento común. Lo no previsto en este Código se sujetará a lo prescrito en el Código de Procedimiento Civil."

La razón por la cual se debe aplicar el procedimiento análogo de los juicios verbales en materia laboral y en particular en la tramitación del incidente de incompetencia de jurisdicción, conforme lo dispuesto en el Arto. 404 C.T., responde al principio de celeridad instituido en lo laboral, por lo que no es comprensible que se le aplique las normas del procedimiento común ordinario. ${ }^{7}$

\section{Restricción en sede laboral}

En el juicio laboral no es posible la admisibilidad de todas las excepciones que se establecen en el Código de Procedimiento Civil (Pr.), considerando su naturaleza especial ya que esta rama del Derecho Público por su carácter social y como medio para tutelar los derechos de los trabajadores está regido por principios que limitan o restringen la voluntad civilista en las relaciones laborales, así como de que los derechos laborales o prestaciones sociales no pueden ser objeto de negociación entre el trabajador y empleador, son inalienables, irrenunciables y de orden público. Entre esos principios tenemos: ${ }^{8}$

\footnotetext{
${ }^{6}$ Ibídem, pág. 160.

${ }^{7}$ Ibídem, pág. 161.

${ }^{8}$ Título Preliminar, Ley No. 185, Código del Trabajo, Gaceta No. 205 del 30 de octubre de 1996.
} 
6.1 Los derechos reconocidos en el Código del Trabajo son irrenunciables.

6.2 El ordenamiento jurídico laboral limita o restringe el principio civilista de la autonomía de la voluntad y en consecuencia, sus disposiciones son de riguroso cumplimiento.

6.3 En caso de conflicto o duda sobre la aplicación o interpretación de las normas del trabajo legales, convencionales o reglamentarias, prevalecerá la disposición más favorable al trabajador; $y$

6.4 Las normas contenidas en el Código del Trabajo y la legislación laboral complementaria son de derecho público, por lo que el interés privado debe ceder al interés social.

\section{Concepto de incompetencia de Jurisdicción}

La Jurisdicción “es la potestad de administrar justicia, o sea, el derecho y obligación de aplicar la ley" (Arto. 1 Pr.); y la Competencia "es la facultad de conocer de un negocio determinado (Arto. 2 Pr.). Por lo tanto la Incompetencia de Jurisdicción en términos generales es la inhabilidad para conocer de un asunto en particular al haber una oposición a al conocimiento de un asunto que por la ley misma ha sido confiado a otros órganos o autoridades judiciales. ${ }^{9}$

En el Juicio Laboral como herramienta jurídica persigue ventilar previamente la esencia misma de la competencia del órgano conocedor de una demanda para resolver el conflicto laboral. Es un medio procesal dilatorio para mantener, según la perspectiva de una de las partes procesales, la pureza del conocimiento de la autoridad laboral para que la resolución sea apegada a la ley. Por supuesto como incidente de previo y especial pronunciamiento no siempre es utilizado sanamente sino que de forma instrumental se opone para la demora del proceso y el agotamiento de la contra parte en sus gestiones.

La excepción de Incompetencia de Jurisdicción es la que radica en la falta de competencia del órgano para conocer de la acción. En lo laboral abarca la cuantía, materia, y el territorio. Es un presupuesto procesal y su ausencia produce la nulidad de todo lo actuado. Como excepción dilatoria es la falta de competencia de un Juez o Tribunal para conocer de una demanda particular. Es una excepción utilizada de forma amplia y general en materia civil, pero en el aspecto laboral su ámbito es reducido por la naturaleza misma del Derecho Laboral. Es decir que la ley les confiere privativamente al Juez la competencia la que difícilmente se podría poner en duda, tal a como sucede en demandas civiles por razón de materia, cuantía y territorio. Al oponerse esta excepción junto a otras, no se afecta la reso-

${ }^{9}$ COUTURE, Vocabulario Jurídico, 1993, págs. 328. 
lución de aquellas puesto que de previo se tiene que resolver la de Incompetencia de Jurisdicción por la razón de que debe dilucidarse la competencia del Juez para que pueda examinar las otras en la sentencia definitiva.

\section{8. Ámbito de aplicación}

Establece el Arto. 273 C.T. en su primera parte que los jueces del trabajo conocerán única y exclusivamente de la materia laboral y de igual forma el Arto. 275 del mismo Código determina, en lo conducente, "que los jueces del trabajo conocerán en primera instancia dentro de sus respectivas jurisdicción de los conflictos individuales y colectivos de carácter jurídico que surjan entre empleadores y trabajadores, sólo entre aquellos o sólo entre éstos (...) conocerán además de denuncias de carácter contencioso que ocurran con motivo de la aplicación de la Ley de Seguridad Social y de las faltas cometidas contra las leyes del trabajo (...)." La Ley Orgánica del Poder Judicial (LOPJ) en su Arto. 49 determina la competencia de los Juzgados de Distrito del Trabajo al especificar que tendrán competencia para "conocer y resolver los conflictos originados en la relación laboral... y de que tendrán competencia para conocer y resolver los asuntos de previsión y seguridad social, con fundamento o no en relaciones laborales." En otras palabras el Código del Trabajo y la Ley Orgánica del Poder Judicial de manera privativa han conferido competencia a los Juzgados del Trabajo para que conozcan en primera instancia dentro de sus respectivas jurisdicción de los conflictos individuales y colectivos de carácter jurídico que surjan entre las partes que expresamente detalla; así como de conocer denuncias de carácter contencioso que ocurran con motivo de la aplicación de la Ley de Seguridad Social, de forma básica y general.

Analizando los alcances del Arto. 275 C.T., tenemos que el Juez del Trabajo tendrá competencia para resolver:

- Los conflictos individuales y colectivos de carácter jurídico que se presenten entre trabajadores y empleadores;

- Los conflictos individuales y colectivos de carácter jurídico que se presenten entre los mismos trabajadores;

- Los conflictos individuales y colectivos de carácter jurídico que se presenten entre los mismos empleadores.

Los conflictos se derivarán de la aplicación del Código del Trabajo, de las leyes, decretos y reglamentos de trabajo, del propio contrato de trabajo o de hechos que estén íntimamente relacionados con el contrato laboral.

- Las denuncias de carácter contencioso que ocurran con motivo de la aplicación de la Ley de Seguridad Social; y 
- Faltas cometidas contra las leyes del trabajo, con facultad de aplicar las penas consiguientes.

Conforme el Código del Trabajo los conflictos jurídicos colectivos pueden ser promovidos por un grupo de trabajadores si no existiere sindicato en el centro de trabajo o por el sindicato si hubiere (Arto. 370), ante el Juez del Trabajo previo agotamiento de la vía administrativa laboral. Los Jueces del Trabajo también tienen competencia de carácter especial en los conflictos colectivos de carácter económico-social en los siguientes aspectos: a) En la conciliación ya sea para la ejecución del acuerdo o el pago de los daños y perjuicios ocasionados (Arto. 382 C.T.); y b) Cuando se tenga que dar el cumplimiento al Laudo Arbitral (Arto. 400 C.T.).

El conflicto individual clásico que se presenta en lo laboral es cuando se da la disolución o terminación de la relación laboral en donde el trabajador se considera violentado en sus derechos laborales, ya sea porque no le fueron reconocidos los derechos que estima le deben tutelarse o por el interés de mantener la relación laboral existente. La terminación puede ser por despido o renuncia, además por mútuo acuerdo.

Al darse el despido de un trabajador o bien que éste renuncie se puede presentar el hecho de que el trabajador al recibir el pago de todas sus prestaciones de ley, o lo que se denomina "liquidación final" puede considerar que no le fueron bien pagadas teniendo la oportunidad de entablar demanda con acción complementaria de pago por esas prestaciones, o porque el empleador por otras causas se negare a cancelar las prestaciones al trabajador. Para los despidos que violenten lo establecido en la norma del Arto. 46 C.T., y a consideración del trabajador afectado éste puede demandar el reintegro invocando las normas objetivas competentes que señala el Código del Trabajo. O bien que el trabajador despedido se considere trabajador de confianza por lo que ejercerá el derecho en base al Arto. 47 C.T.

\section{Procedimiento}

El procedimiento para tramitar la excepción de incompetencia de jurisdicción es breve y sencillo. Una vez presentada la demanda en su debida forma el demandado deberá hacer valer sus derechos en la contestación y en ese mismo acto oponer las excepciones que considere oportunas. De oponerse la Incompetencia de Jurisdicción se detendrá el proceso y se abre el incidente en el mismo expediente procesal, teniendo la otra parta del derecho de expresar lo que tuviera a bien, y el Juez resolverá la excepción con o sin período de prueba. De los que resuelva 
el Juez se podrá interponer los recursos de impugnación que establece el Código del Trabajo y si fuere el de Apelación se esperará la resolución que emita la Sala Laboral del Tribunal de Apelaciones competente. Una vez resuelto el recurso de apelación las diligencias se remitirán al Juzgado de origen para continuar con el proceso laboral o el archivo del mismo.

De no oponer el demandado la incompetencia de jurisdicción no significa que el Juez conocerá de la acción cuando la misma el judicial descubriere que no es del resorte laboral, sino que por el contrario de forma oficiosa el Juez podrá declararla para la pureza del proceso y salvaguarda de los derechos de las partes. Resulta sorprendente imaginarnos que existan demandas en vía laboral que no tienen nada que ver con la misma, pero se han presentado casos de esa naturaleza lo que nos conlleva a reflexionar mejor un caso para evitarnos pérdidas de tiempo y recursos económicos.

\section{Conclusiones}

En términos generales la excepción de INCOMPETENCIA DE JURISDICCIÓN como medio procesal es utilizado principalmente por la parte demandada quien es en este caso el empleador o patrón y el objetivo inmediato es la dilatación del proceso judicial considerando que algunos trabajadores no cuentan con el apoyo económico para enfrentar los costos de honorarios abogadiles, lo que conllevaría quizás a un abandono del proceso por parte del actor. Así mismo como es la forma de atacar la competencia del órgano juzgador está revestida de una característica especialísima: Su resolución incide mucho en cuanto a mantener incólume el derecho subjetivo de la parte actora para que en caso de que se declare con lugar, el demandado pueda enderezar correctamente su acción ante la autoridad que tiene por ley, la competencia para resolver el conflicto laboral dentro del término que señala la misma ley para que no haya prescripción. Por la razón antes expuesta ésta excepción al resolverse de previo y especial pronunciamiento, la resolución que dicte la autoridad laboral es considerada como una sentencia Interlocutoria con fuerza de definitiva en la forma ya que al resolver la excepción concluye con el procedimiento únicamente y no con el derecho de la parte actora.

La Sentencia que resuelva este incidente es apelable en ambos efectos ya que es imprescindible que se establezca vehemente y con transparencia la competencia de la autoridad laboral. En este caso el procedimiento laboral exige al Juez que se tramite correctamente la excepción no siendo aplicable de inicio de forma absoluta, lo dispuesto por el Arto. 321 C.T., que manda a que sea rechazada de inmediato y sin ulterior recurso toda excepción propuesta sin ningún fundamento con 
el fin de retrasar el proceso, por lo que el Juez tiene una gran responsabilidad ya que debe valorar objetivamente el alegato de la parte oponente de la excepción para resolver lo pertinente.

En nuestro sistema jurídico laboral en términos generales a priori el Juez no determina si es o no competente para conocer de la demanda sino que dicha responsabilidad la deja directamente en poder del demandado quien deberá oponerla en el mismo acto de la contestación de la demanda, para mantener la imparcialidad y transparencia procesal. Sin embargo si la parte demandada no opone la excepción de incompetencia de jurisdicción y el Juez estima que la acción no es del resorte laboral así lo declarará para la buena marcha del proceso que es de orden público. El Código del Trabajo señala que la demanda deberá estar revestida de ciertos requisitos esenciales y formalidades para que sea admitida por el Juez del Trabajo y establece que si una demanda no contuviere los requisitos la autoridad judicial ordenará al actor la subsanación de los mismos.

La Sala Laboral del Tribunal de Apelaciones de la Circunscripción de Occidente en relación a esta situación, en su Sentencia No. 131 de las cuatro y quince minutos de la tarde del 23 de Noviembre de 1998, Considerando II, Páginas 731/732; publicada en extracto por los Doctores Octavio Martínez Ordóñez y Saúl Castellón Tórrez en su obra Diccionario de Jurisprudencia Laboral de Occidente 1997-2001, página 117 se dijo:

"JUEZ DEL TRABAJO (Forma de proceder).- Como primer presupuesto todo Juez del Trabajo, debe constatar si quien demanda llena los requisitos establecidos en el Arto. 19 C.T., es decir, el Judicial debe asegurarse de la existencia de la relación laboral o de trabajo, entre el demandante y el demandado. Establecida ésta, determinará las pretensiones comprendidas en la demanda del trabajador. Entre ellas distinguir las comprendidas como de ineludible cumplimiento y que se prueban con el transcurso del tiempo, y las que dependen de la voluntad nacida de la relación laboral establecida entre el trabajador y el empleador".

En algunas legislaciones de otros países se contempla la alternativa de que la autoridad judicial, aunque la parte demandada no lo alegue, deberá analizar la acción interpuesta y decidir si la misma es de su competencia antes de que dicte sentencia, sea el Juez de Primera Instancia o la Sala del Tribunal de Alzada, dándole intervención al representante de la Procuraduría General del Estado y a los interesados. En nuestro sistema dentro de un litigio laboral entre particulares no se le pone en conocimiento de las diligencias al Estado por medio de la Procuraduría Laboral, sino que ésta únicamente representa al Estado como actor o demandado en sus asuntos propios. 
$\mathrm{Al}$ ordenar nuestro Código Laboral que ésta excepción deberá oponerse en el mismo acto de la contestación de la demanda no significa que opere la denominada "sumisión tácita" conocida en el Derecho Procesal Civil por ser el Derecho Laboral una rama del Derecho con normas especialísimas que priman por sobre las otras normas jurídicas estimando los principios del Procedimiento Laboral.

Finalmente la ley laboral establece que de presentarse un conflicto de competencia entre Jueces del Trabajo, por ejemplo en razón del territorio, será resuelto dicho conflicto por el Tribunal de Apelaciones respectivo. Es decir el superior jerárquico común de ambos Jueces. De no haber Tribunal de Apelaciones el conflicto lo dirimirá directamente la Excelentísima Corte Suprema de Justicia. Esta situación de conflicto podrá ser a solicitud de parte interesada o de oficio y el órgano superior resolverá lo que sea procedente dentro de tercero día después de haber recibido los autos y remitirá lo resuelto al Juez del trabajo considerado competente para que continúe o reanude el procedimiento de oficio (Arto. 280 C.T.).

\section{BIBLIOGRAFÍA}

- CABANEllas guilleRMO, Diccionario Enciclopédico de Derecho Usual Tomo III, Editorial Heliasta 25a. Edición. Buenos Aires, Argentina. 1997.

- Código de Procedimiento Civil.

- Couture, Vocabulario Jurídico, Editorial Depalma. Buenos Aires, Argentina. 1993.

- HUEMBES Y HUEMBES JUAN, Nuevo Diccionario de Jurisprudencia Nicaraguense. Masaya. 1971.

- Ley No. 185 "Código del Trabajo", publicado en La Gaceta, Diario Oficial No. 205 del 30 de Octubre de 1996.

- Ley No. 260 “Ley Orgánica del Poder Judicial de la República de Nicaragua”, publicada en La Gaceta, Diario Oficial No. 137 del 23 de Julio de 1998.

- MARTÍNEZ ORDÓÑEZ OCTAVIO Y CASTELLÓN TÓRREZ SAÚL, Diccionario de Jurisprudencia Laboral de Occidente 1997-2001. Editorial Universitaria UNAN-LEON. 2002.

- ORTÍZ URBINA ROBERTO J. Derecho Procesal Civil, Editorial Bitecsa, Managua. 1995. 